\title{
FACTORS AFFECTING TEACHING ABILITIES, PRACTICES AND MOTIVATION - EVIDENCES FROM SENIOR SECONDARY SCHOOLS IN DELHI
}

\author{
Charu Jain ${ }^{1}$ and Narayan Prasad ${ }^{2}$ \\ ${ }^{I}$ National Council of Applied Economic Research (NCAER), India \\ ${ }^{2}$ Indira Gandhi National Open University (IGNOU), India
}

\begin{abstract}
Worldwide research provides ample evidences that teachers play an important role in learning level of students. Hence, improving the quality of teaching process may be one of the effective means of raising pupil achievement levels. One might expect that teachers themselves are committed to improve the quality of education. However, in reality often gaps are observed between the expectations of the society and the way in which teachers practice their profession. Based on the survey data collected from senior secondary schools in Delhi, this paper aims to identify gaps in the importance-satisfaction scale of teaching profession and investigating various obstacles faced by teachers in adopting efficient teaching practices in schools using factor analysis technique. The findings reveal four broad dimensions affecting teaching practices: school factors, teaching factors, external and non-teaching factors. Results suggests that while, government should ensure timely allocation of funds and support to schools, the schools should be able to utilize these funds in best possible ways in creating healthy environment, where both students and teachers can reflect higher motivation to learn, practice and participate. This paper emphasizes that quality teaching is a multidimensional process and therefore all associated elements need to work in collaboration.
\end{abstract}

Keywords: Factor Analysis Technique, Quality Education, Secondary Education, Teaching Practices

\section{Introduction}

Indian secondary education system not only provides a crucial link between primary and higher education but also provides strong human capital base for the country. Moreover, with successful completion of Sarva Siksha Abhiyan (SSA), one of the largest program run by government for universalisation of primary education in India, the demand for secondary education has increased further. Therefore, to reap its full benefits in terms of private and social returns, there is need to shift focus from mere 'Quantity' expansion to 'Quality' improvement. The worldwide research consistently demonstrates that teachers are important factors in improving learning and achievement level of students. According to Hanushek (2002), teacher quality is the key to improved schools. Another study shows that the combined variables of teacher quality and instructional strategies are correlated with student achievement (Okoye, Momoh, Aigbomian and Okecha, 2008). Torff (2005) purports that lack of pedagogical skill and knowledge is a bigger threat to teacher quality than are certification issues. Berliner (2005) describes 'quality teachers' as those who show evidence of certain qualities of teaching: logical, psychological and moral acts of teaching in the lives of students.

However, there remains an unresolved debate on difference between 'teacher's quality' and 'teaching quality'. According to Intercultural Development Research Association (IDRA), teaching quality is a multi-layer approach that refers not only to the teachers' credentials, but also to the perspective that teachers bring to the classroom, the instructional strategies that they use, and the surrounding organization of the school and community. Recently, one of the newsletters by Harvard School of Education asserts that the definition of "quality" teaching needs to be linked to whether specific teaching practices are supporting children's learning of a broad range of social, cognitive, and specific academic skills (Susan H. Landry, 2016). 
One might expect that teachers themselves are committed in improving the quality of education. It is true that individual teachers are important contributors to student achievement, but they are not the only contributors. The quality of teaching in a school depends on more than just individual teacher quality. It depends on other factors as well such as the amount and quality of instructional resources available, teacher professional development, staffing, and support from administrators and parents. If schools are not well organized and supportive, it is possible that even good teachers will not be successful (Raudenbush et al., 1992). Successful teaching depends on many factors, including the level of instructional resources available, staffing levels, continuing professional development, and support from administrators and parents (Johnson, 1990).

It is clear from above discussion that that improving the quality of teachers and teaching process may be one of the effective means of raising overall quality of education in schools. Today, teaching is not just confined to classrooms learning with restricted curriculums. The definitions of what teachers should know and be able to do have changed over time with change in society's values and students coming from varied backgrounds with different learning and language needs. The job of teaching students to learn and use new information, develop and apply skills, and think critically is highly complex and demanding. Teachers need a wide range of knowledge, skills, abilities, and dispositions to perform these many complex tasks.

However, in reality often gaps are observed between the expectations of the parents or society and the way in which teachers believe that they should practice their profession. This paper emphasizes that making teaching most effective is not just one dimensional term as it depends upon number of ways in which other resources works in combination. It is against this background that the research need arose to examine all those dimensions that may have direct/ indirect impacts on the quality of teaching. The paper portrayals not only the existing working environments and teaching practices adopted in senior secondary schools in Delhi, but also brings out various obstacles faced by teachers in achieving their professional goals. Through this study, an effort has been made to capture teacher's perspective on the overall situation of teaching quality in schools.

The paper is divided into six sections; while the first section provides the introduction, the need to conduct this study, major objectives of this study and research questions. The second section, describes the research methodology covering study area, research design, study methods, limitations and significance of the study, while third section presents the major survey findings including teachers characteristics and working profile. The fourth section examines various factors that affect the quality of teaching practices in schools. The model and results constitutes the fifth section, while the last section summarizes the findings of this study.

\section{Purpose and Objectives of the Study}

The purpose of this study is to investigate the factors affecting the efficiency of teaching abilities and practices along with the motivation level of teachers. Specifically, the objectives of this study are:

- To study various socio-demographic, educational and teaching characteristics of respondent teachers in selected senior secondary schools in Delhi.

- To examine the existing working environment in schools where teachers practice their profession.

- To identify the factors that are considered to be the most important by teachers in enhancing their professional growth or motivation level and ranking their satisfaction level on each of these important indicators to analyze where exactly the mismatch is. Along with this, the paper also seeks to capture the variations in the importancesatisfaction parameters by type of school ownership.

- To develop a model that could identify various factors affecting the efficiency and teaching abilities of teachers and restricting them in adopting best teaching practices in schools. 


\section{Research Questions}

The following specific research questions guided the study:

- Does working conditions in schools or school resources or infrastructural facilities affects teaching abilities and if yes, how?

- Whether salary, job stability or promotions affects their motivation level of teachers?

- Does changes in educational policy or other external interferences plays any role in improving teaching quality in schools?

\section{Research Methodology}

\section{Study Area and Population}

The capital city of India, Delhi, formed the study area. Delhi accounts about 0.05 percent of the India's geographical area and consists 1.38 percent of the nation's population. As per Census 2011, population of Delhi was 16.75 million, with 97.5 percent of the population living in urban area. With high level of literacy of 86.3 percent in 2011, Delhi has made considerable educational progress over the years with improved access to educational facilities and high enrolment rates. To meet the objectives, study, undertakes primary survey in 41 sample senior secondary schools including private and government schools registered with the Directorate of Education. From selected sample schools, the target respondents were selected for the face to face personal interviews. The target respondents were teachers teaching in lower and senior secondary levels of education (Class IX-XII).

\section{Sample Size}

Generally, there is no definite recommendation for the appropriate sample size and researchers end up with the sample sizes based on their financial limitations, time or cost availability. However, it is important that besides these limitations, we should calculate the sample size with acceptable or reasonable precision. The literature shows that the sample size in most of social science studies is calculated using confidence interval, confidence level and degree of precision. Generally, the rule is that wider the confidence interval; the more certain researcher can be that whole population answers would be within that range. We have used the following methodology for sample size calculation (Daniel, 1999).

$$
n=\frac{Z^{2} P(1-P)}{d^{2}}
$$

Where $\mathrm{n}=$ sample size; $\mathrm{Z}=\mathrm{Z}$ statistic for a level of confidence; $\mathrm{P}=$ expected prevalence or proportion; and $\mathrm{d}=$ precision or confidence interval expressed as decimal.

Using this method, maximum sample size is selected at 95 percent confidence interval level that satisfies the assumption of normal approximation. Considering this methodology, 160 teachers are selected for the purpose of personal interviews. The sample size is justified on the grounds of limited resources available and time constraints.

\section{Sampling Design}

A two-stage stratified systematic random sampling technique is considered for the collection of survey data. At first stage, sample schools are selected, while in second stage teachers are selected for the interviews. Under first stage, for selection of sample schools, a well defined sampling frame was required which was taken from the Directorate of Education in Delhi, consisting of detailed information of more than 2200 registered schools, of which 43.4 percent of schools are government owned, while remaining 56.6 percent are public recognized schools. The sampling frame provided detailed information on school Id's, school name, enrolments and 
complete address. The list of schools was distributed across 28 administrative zones and 12 administrative districts (as per the Census of India 2011), which were re-classified into 4 regions north, south, east and west for wider coverage. For selection purpose, the total schools were divided into eight stratums based on four regions and school ownership type i.e. government and private. From each of the eight stratums, four schools (2 government schools and 2 private schools) were covered through systematic random sampling. However, in case of government schools, it was found that due to shortage of classrooms, the schools were organized in morning and evening shifts (apart from few co-ed schools), separately for boys and girls in Delhi, where each shift is considered as separate school. Therefore, we have about 25 government schools and 16 private schools in our sample, together accounting for 41 sample schools in all.

After schools selection, the second stage was the selection of sample teachers. For this, 5 teachers from each school were selected randomly for various subjects teaching classes from IX-XII. In case of government schools, where separate morning and evening shifts operates, 3 female teachers from girl's government schools and 2 male teachers from boy's government schools were covered. Although, it was a random process to select teachers from respective schools but their willingness to participate in this survey was also taken into consideration, hence no quota was fixed for teacher selection between lower and senior secondary levels. On whole, 160 teachers were covered in our sample for personal interviews, constituting 80 teachers each by private and government schools. The survey was conducted during the period Sept-Dec 2013.

\section{Study Method and Data Collection Instrument}

The quantitative research approach is adopted for the study. Interviews and questionnaires are the main sources through which data were gathered. For this, a structured questionnaire was used to elicit information from the teachers including quantifiable and non-quantifiable variables. Through questionnaire, the information was captured from sample teachers under five broad sections; teachers characteristics, their educational and socioeconomic background, school resources and infrastructure, teaching practices and aptitude, their opinion on various issues related to quality of education and self development/ satisfaction levels. To rule out the possibility of non responses, few extra questionnaires were canvassed.

\section{Data Methods and Techniques}

Both open and close ended questions were asked from the respondent teachers. In certain cases, to capture their perceptions and satisfaction level on various quality issues related to school facilities, teaching practices, students understanding level, professional development etc, ranking and scaling methods were adopted, the responses of which have been presented here in the form of percentages or weighted average scores. Data analysis in this paper has been carried out using both bivariate and multivariate techniques. While, bivariate analysis includes tabulations and two dimensional plot, multivariate techniques includes factor analysis technique.

\section{Limitations of the Study}

Although efforts have been made to cover all aspects including quantifiable and non quantifiable variables which are affecting the teachers performance, their motivation level, achievements, abilities and satisfaction, however, there might be certain other for example psychological or personal factors which are not covered in this study but may have impacts.

\section{Significance of the Study}

The findings in the paper are expected to bring a change in the general mindset that improving the quality of teaching in schools is not only the responsibility of teachers but of overall system in which number of others factors works in combination. The study will help in identifying various factors that strongly influences the performance and motivation level of the teachers. The findings can suggest the ways for enhancing the expertise 
and motivation of teachers towards achieving the common goal of quality education and raising learning outcomes in schools.

\section{Major Survey Findings: Teachers Characteristics and Working Profile}

This section presents the major survey findings related teacher's characteristics including their sociodemographic profile, educational background and teaching characteristics along with the working profile that includes working conditions in schools, present situation of teaching and non teaching practices and professional growth.

\section{Socio-Demographic Characteristics of Teachers}

The respondent teachers are equally distributed between private and government schools. Nearly 33 percent of teachers covered in our sample are males, while remaining 66.9 percent are females. About 71 percent of the respondent teachers are teaching in Co-educational schools, this proportion is 11 percent and 18 percent in case of boys' and girls' schools respectively. Table 1 shows that majority of the teachers are above 40 years of age and are married. About 72 percent of the teachers have passed out their highest education through 'English' medium, while remaining 28 percent through 'Hindi' language as their medium of study. In total, nearly 86 percent of teachers with either graduate degrees or above also possess teacher training degree, while about 12 percent of teachers although have attained graduation or higher degrees but don't possess teacher training degree which is essential in this area to perform better.

\section{Teaching Characteristics}

The survey further shows that about 68.8 percent of teachers are working as Trained Graduate Teachers (TGTs) i.e. eligible to teach upto classes $X^{\text {th }}$. Post Graduate Teachers (PGT) teachers i.e. those eligible to teach $\mathrm{XI}^{\text {th }}$ and $\mathrm{XII}^{\text {th }}$ standard constitutes 31.2 percent of total share in sample. Almost 67 percent of teachers are teaching in English medium schools, whereas this proportion is 33 percent in case of Hindi medium schools. About 61 percent of teachers in the sample are teaching lower secondary classes, 28 percent are teaching senior secondary classes, while remaining 12 percent are teaching both levels of secondary education. The teachers covered in our sample are well experienced teachers with on an average of nearly 15 years of total work experience (Table1). Only two-third of sample teachers has attended trainings in last 5 years. This proportion is higher in private schools compared to that of government schools.

Table 1 Distribution of Teachers by Socio-Demographic and Teaching Characteristics

\begin{tabular}{llc}
\hline Characteristics & Description & \% of Teachers \\
\hline Socio-Demographic Profile & & \\
Age Categories & Upto 30 years & 23.8 \\
& $30-40$ years & 20.6 \\
& $40-50$ years & 43.1 \\
& $>50$ years & 12.5 \\
Marital Status & Unmarried & 11.3 \\
& Married & 86.9 \\
& Widow/Widower & 1.9 \\
Qualification & Graduate without training & 2.5 \\
& Graduate with training & 43.8 \\
& Post Graduate without training & 10.0 \\
& Post Graduate with training & 41.3 \\
\hline
\end{tabular}




\begin{tabular}{lll}
\hline & M.Phil/Ph.D with training & 2.6 \\
Teaching Characteristics & & \\
Designations & Trained Graduate Teachers (TGT) & 68.8 \\
& Post Graduate Teachers (PGT) & 31.2 \\
Experience (in yrs) & Upto 10 years & 35.0 \\
& 10-20 years & 39.4 \\
& Above 20 years & 25.7 \\
Medium of Instructions & English & 66.9 \\
& Hindi & 33.1 \\
\hline
\end{tabular}

\section{Working Conditions in Schools}

Despite this fact that most of the senior secondary schools in Delhi provide all necessary facilities to students/staff due to high completion, there exists a significant difference between government \& private schools. Private schools are ahead of government schools in providing most of the facilities like well equipped smart classrooms with proper lighting, window panes and ventilation, canteens, electricity supply, school transport, separate toilets and safe drinking water. The study further suggests that non availability of facilities in schools in not the issue, the main problem is poor conditions of available facilities, thus pointing towards lack of proper maintenance and regular servicing of the resources. For e.g. science labs in government schools lack modern equipments, libraries lack sufficient reading references, water purifiers lacks regular servicing and smart class technique lacks optimum usage. Lack of sufficient resources leads to low motivation to teach. The conditions are worst in case of the most basic facilities of food quality in canteens, cleanliness/ lightening and water supply in toilets and water purifier conditions thus pointing towards serious health implications.

\section{Teaching Practices and Aptitudes}

The survey shows that although majority of teachers are teaching the subjects of their specialized area, yet there is certain proportion of teachers ( 7 percent) who are even teaching non specialized subjects. This can have a great impact not only on teaching abilities of such teachers but also on learning and achievement level of students. In case of teaching aids, more than 90 percent of teachers are using backboards or whiteboards, followed by equipments that are more or less restricted in science teaching, indicating lacks of sufficient and modernized teaching aids due to which teachers fails to develop students interest. Even in schools where smart class techniques are available; its usage is not upto mark due to lack of necessary skills and lack of time due to pressure of covering up the syllabus. Along with this, the survey also highlights the huge gap in teacher-student interaction.

\section{Non-Teaching Practices}

In addition to teaching responsibilities, teachers are also involved in many other activities related to admissions, curriculum designing, functioning of school, managerial activities etc which lay an impact on their teaching capabilities. Among non teaching practices, the most prominent practices are marking papers and organizing schools activities, as mentioned by almost 86 percent and 77 percent of sample teachers. Nearly 29 percent of teachers are involved in handling school publications, while 26 percent help in setting examination papers. 


\section{Professional Growth}

Nearly 34 percent of the surveyed teachers have not attended any training since last five years. This proportion is higher in private schools. Reasons are: lack of opportunities and time, irrelevant to their subjects and doesn't help them in improving their skills. Cost associated with trainings is another issue. Among those who have not attended the trainings, majority of teachers believes that most of these trainings organized for professional development of teachers neither provide any linkage between theory and practice, nor do they benefit them in improving their teaching skills/ learning new technologies.

\section{Factors Affecting Professional Growth: Leading to Inefficient Teaching Practices}

This part of the paper is important in the sense that it not only plots two-dimensional importance-satisfaction scale for indicators considered to be important by teachers for professional growth and higher motivation against their satisfaction level, but also investigate various factors that restricts the teachers in adopting best efficient teaching practices in schools.

\section{Importance-Satisfaction Scale}

This section plots various factors that respondent teachers consider to be most important for professional growth and in enhancing their motivation level against their level of satisfaction with these indicators. The responses for both importance and satisfaction of teachers on pre listed indicators were taken on 5 point likert scale for which the average scores were calculated and accordingly a priority list was prepared reflecting the highest important/satisfaction factor followed by next highest and so on. To better present the indicators with their importance and satisfaction level, a two-dimensional scatter diagram (Importance-Satisfaction Scale) was plotted. While Y-axis plots indicators on the basis of their importance scaling from high to low, the X-axis plots satisfaction scale from low to high. Figure $1 \& 2$ reflects differences in the vision of teachers between private and government schools on various factors which they consider to be most important for their professional growth and their satisfaction level.

The figure is further divided into 4 zones; A, B, C and D. Among all zones, zone B is the influential zone which can be considered as positive strength of schools that motivate teachers to perform better as it offers higher satisfaction to teachers for the factors that are considered to be the most important. On the other hand, zone A is the most critical zones restricting the professional growth of teachers because although the indicators falling in this zone are important for teachers but ranks low on satisfaction.

The findings reveal that in case of Importance-Satisfaction Scale for private schools, the factors that are considered to be important for teachers professional growth but ranks low on satisfaction scale are job security and training opportunities to some extent. Best performing indicators are high student motivation, gaining quality experience and self development opportunities (Figure 1). On the other hand, Importance-Satisfaction Scale for government schools reveals that among factors which are important for teachers professional development but scores low on satisfaction scale are lower student motivation and lack of self development opportunities. Best performing indicators in this case are job security, salary increments, promotion and quality experience (Figure 2).

Overall, this section highlights the need to understand various factors which demands importance in the professional life of teachers and how far schools have been able to satisfy teachers on those indicators. There is need to workmore on issues like job security, salary increments and better training opportunities for teachrers in private schools, while in case of gvernemtn schools, low students motivation and lower selef development opportunities are major lacking areas. It is clear from above discussion, that if schools want to improve the quality of teaching then they must first focus their strategies in enhancing the morale and motivation level of 
teachers. It is important to make them feel enthusiastic about their profession so that they can use best teaching practices and aptitudes in order to create healthy learning environment. However, this is possible only when school authorities are giving them equal opportunities to achieve their professional goals.

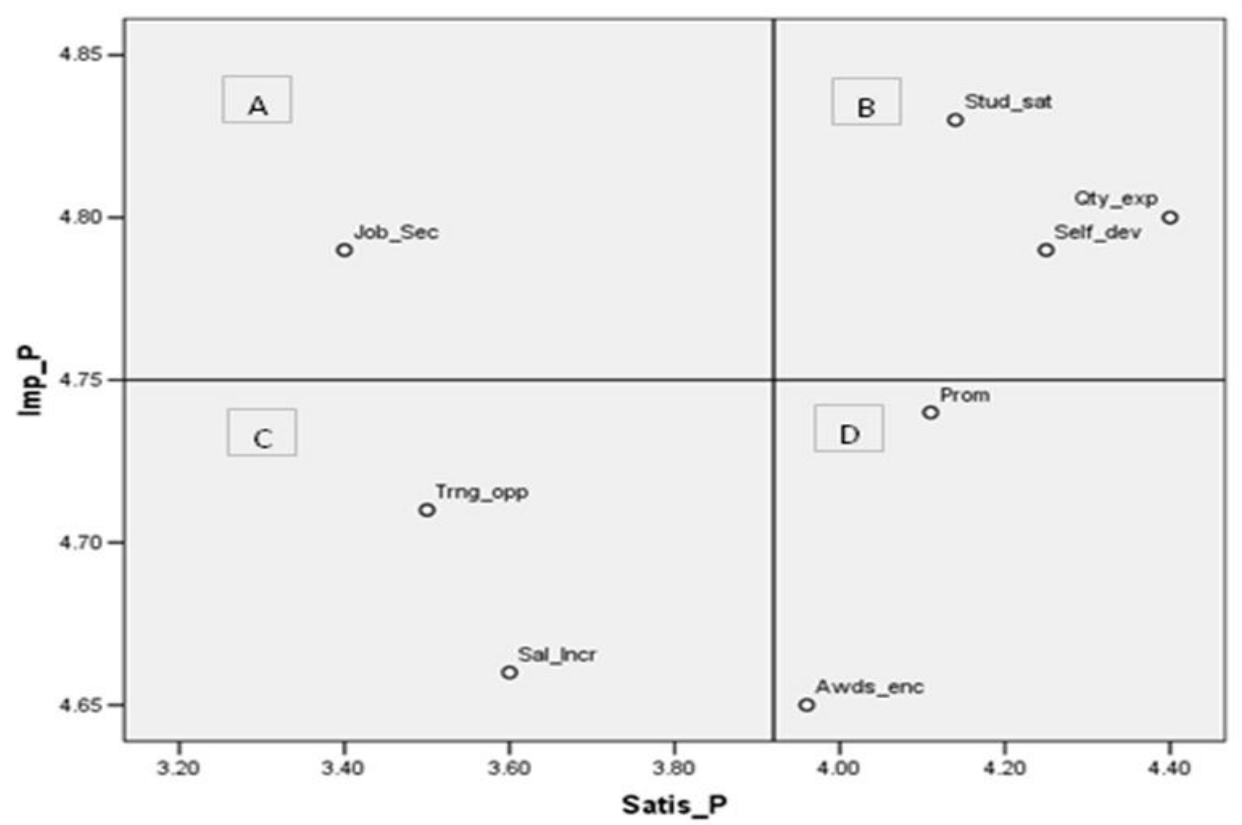

Figure 1 Two dimensional plot showing responses of teachers in private schools on importance - satisfaction scale

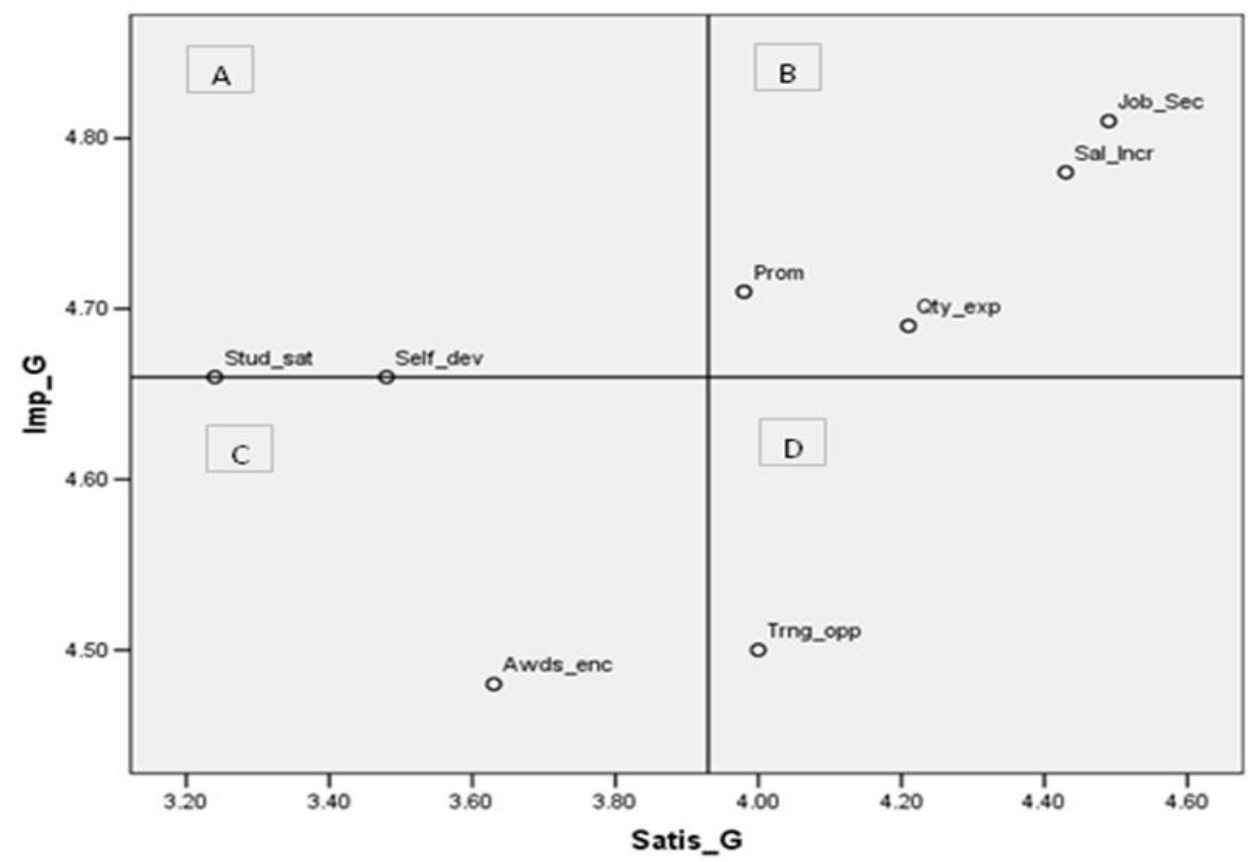

Figure 2 Two dimensional plot showing responses of teachers in government schools on importance satisfaction scale 


\section{Factors Affecting Efficient Teaching Practices}

It is generally seen that even competent teachers in schools fails to enhance the quality of teaching and pupil achievement levels. There are numerous obstacles that frequently challenge these teachers in classrooms, for example, low wages, precarious social status, poor working conditions, heavy workload, large class sizes, limited prospects for professional advancement, etc. To understand few such obstacles, responses have been captured from the teachers on various factors that make overall efforts unsupportive for them and restrict them to adopt efficient teaching practices. Table 2 presents the descriptive statistics in terms of average scores and standard deviations on various obstacles faced by teachers. Table shows that larger proportion of teachers has rated lack of student motivation and large class size as main factors which are affecting their teaching abilities the most. This is followed by factors like lack of resources and facilities provided by schools, huge work load of additions duties and responsibilities due to which teachers get less time for their lessons planning.

Table 2 Descriptive Statistics on Various Obstacles in Efficient Teaching Abilities

\begin{tabular}{lcc}
\hline Factors & Mean & Std. Dev. \\
\hline Lack of school resources and facilities & 2.76 & 1.349 \\
Lack of students motivation to learn & 2.81 & 1.256 \\
Large class size & 2.80 & 1.228 \\
Lack of time for planning lessons & 2.48 & 1.165 \\
Lack of adequate teaching material/ aids & 2.44 & 1.227 \\
Lack of professional trainings & 2.35 & 1.255 \\
Interference from Seniors & 2.24 & 1.179 \\
Interference from Parents & 2.31 & 1.193 \\
Polices interferences & 2.40 & 1.275 \\
Huge work load of additional responsibilities & 2.54 & 1.278 \\
Frequent changes in curriculums, structure & 2.38 & 1.170 \\
Others & 1.60 & 1.265 \\
\hline
\end{tabular}

\section{Results and Discussion}

\section{Factor Analysis Model}

To better understand the affects of above discussed indicators on quality of teaching, factor analysis technique has been used here. Factor analysis is a technique where each variable is modeled as a linear combination of a small number of 'factors' with the addition of a random component term, a little like regression analysis (Cooper and Weekes, 1983). The factor analysis model takes the following form:

$X_{l}=k_{l 1} F_{l}+\ldots \ldots \ldots . .+k_{l m} F_{m}+u_{l}$

$X_{2}=k_{21} F_{1}+\ldots \ldots \ldots . .+k_{2 m} F_{m}+u_{2}$

Where, $\mathrm{m}$ denotes the number of factors in the model and $\mathrm{m}<=$ number of variables. Unlike regression analysis, the factors $F_{1}, F_{2}, \ldots . . F m$ are hypothetical variables. This method will reload the factors into structures with 
similar themes and thus will provide us clarity on what kind of factors affects the teaching abilities most. The findings of the model are presented in Table 3.

\section{Interpretation of Results}

- The value of KMO statistics is 0.86 which indicates that the model is good enough and we should be confident that factor analysis is appropriate on these data sets.

- Bartlett's test measures the null hypothesis that the original correlation matrix is identity matrix. The test shows significant results which indicates that $\mathrm{R}$ matrix is not an identity matrix and therefore there is some relationship between the variable we are hoping to include in the analysis.

- Considering the Eigen values greater than 1, 11 linear components were identified using SPSS software, of which four factors have been extracted that together, explains 80 percent of the variance in data. The rotated component matrix table shows that 'school factors' bear greatest influence on teaching abilities accounting for 24.5 percent of explained variance, followed by 'teaching factors' with 24.50 percent of explained variance. The third and fourth highest components are 'external factors' and 'non teaching factors' with nearly 15 percent of explained variance each.

Table 3 Factor Analysis Results: Identifying Factors behind Inefficient Teaching Abilities

\begin{tabular}{lcccc}
\hline Variables & Comp 1 & Comp 2 & Comp 3 & Comp 4 \\
\cline { 2 - 5 } & School & Teaching & External & Non-Teaching \\
& Factors & Factors & Factors & Factors \\
Large class size & 0.83 & & & \\
Lack of students motivation to learn & 0.82 & & & \\
Lack of school resources and facilities & 0.80 & & & \\
Lack of adequate teaching material/ aids & & 0.84 & & \\
Lack of professional trainings & & 0.77 & & \\
Interference from Senior Teachers & & 0.65 & & \\
Lack of time for planning lessons & & 0.51 & & 0.83 \\
Polices interferences & & & 0.80 & 0.73 \\
Interference from Parents & & & & 0.67 \\
Frequent changes in curriculums, structure & & & & \\
Huge work load of additional responsibilities & & & & \\
\hline
\end{tabular}

Notes- Extraction Method: Principal Component Analysis. Rotation Method: Varimax with Kaiser Normalization. (a)Rotation converged in 6 iterations.

\section{Major Findings}

The model has come up with four broad factors having maximum influence on quality teaching. These factors are discussed as follows:

School Factors: The finding shows that lack of proper school facilities are the greatest obstacles in efficient teaching abilities. Within school factors, the most important is larger class size which affects the effectiveness of teachers. Ideally, the class size should not exceed more than 40 students per class. However, survey shows that the class size is ranging from 50 to upto 120 students per class. This situation would not allow quality teaching and better learning among students as it will not give enough space to teachers to communicate with such a big 
strength at a time. Other important variables included in this component are lack of student motivation and lack of school resources and facilities.

Teaching Factors: This component share same position as school factors do. Within this category, lack of sufficient teaching aids and professional trainings are the most crucial one. This is largely due to the government's inefficiency in providing sufficient funds to schools for acquiring such equipments or schools inefficiency in utilizing funds properly. Moreover, lack of personal development opportunities to teachers is also important factor that inhibits the teaching. In addition, interferences from senior teachers and higher involvement in non-teaching activities also affect their abilities.

External Factors: Along with school and teaching factors, there are certain external factors which affect the quality of teaching. The most crucial among all are policy changes. For instance, changes in grading and examination system which happened recently in Delhi. Then there are policy changes regarding recruitment of teachers etc. The interference from parents from time to time also restricts teachers to implement best practices of teaching.

Non Teaching Factors: The finding also captures the implications of non-teaching factors on teaching abilities. This includes frequent changes in curriculums and burden of additional responsibilities of non-teaching work.

\section{Concluding Remarks}

It is evident from the findings that availability of facilities in schools is not a big issue; the biggest challenge is to have proper functioning and regular maintenance of these facilities. There is need to first focus on improving the poor conditions of most basic facilities: food in canteens, safe drinking water, sanitation facilities and classroom conditions since lack of these facilities reduces motivation to teach. Other factors helpful in enhancing efficient teaching practices in schools are maintaining standard class size, provision of modernized teaching aids, healthy working environment, opportunities for their professional growth and reduction in additional work load.

Along with these initiatives, teachers need to change their own behaviors towards improving the learning processes in classroom. They need to encourage the teacher-students interactions that can lead to higher learning outcomes. The findings further suggests four broad dimensions; school factors, teaching factors, external factors and non-teaching factors, the simultaneous improvement in these factors can improve the overall quality of teaching. While, government should redesign certain policies to ensure timely implementation and delivery of funds, resources, support and supervision to secondary schools, the schools should try to utilize the allocated resources in best efficient ways. Finally, there is need to create an environment in schools where students reflects higher motivation and enthusiasm to learn and participate in various activities.

On whole, paper suggests that quality teaching is a multi-dimensional process where government, schools, teachers, students and society/parents needs to work in collaboration in order to improve the quality of both teaching and learning processes in schools.

\section{Acknowledgements}

The paper is a part of doctoral thesis awarded in April 2015 from School of Social Sciences (SOSS), Indira Gandhi National Open University (IGNOU, New Delhi). We are thankful to all teachers and principals of the selected sample schools in Delhi for providing us the necessary inputs for completing the work. We are thankful to National Council of Applied Economic Research (NCAER) for providing the funding to participate in ICEDU 2016 conference and giving us the opportunity to present the major findings of this paper and seeking suggestions thereof. Last but not the least, the participants at $2^{\text {nd }}$ International Conference on Education (ICEDU) held at Bangkok, Thailand from 21-22 April 2016 are highly acknowledged for their suggestions and comments. The views expressed in the paper are those of the authors and do not necessarily reflect the opinion of the affiliated organizations. 


\section{References}

Ammermueller, A. and Dolton P., 2007, Pupil Teacher Gender Interaction Effects on Scholastic Outcomes in England and the USA, Centre for European Economic Research (ZEW), Discussion paper no. 06-060.

Angeline Barrett et al., October 2007, Initiatives to Improve the Quality of Teaching and Learning, A review of recent literature, Background paper prepared for the Global Monitoring Report 2008, UNESCO 2008/ED/EFA/MRT/PI/12.

Aslam, Monazza \& Kingdon, Geeta, 2011, What Can Teachers do to Raise Pupil Achievement? Economics of Education Review, Elsevier, vol. 30(3), pp. 559-574, June.

Bartlett, James E., Kotrlik, Joe W. and Higgins, Chaadwiick C., 2001, Organizational Research: Determining Appropriate Sample Size in Survey Research, Information Technology, Learning, and Performance Journal, Vol. 19, No. 1, Spring 2001, pp. 43-50.

Berliner, D.C., 2005. The near impossibility of testing for teacher quality. Journal of Teacher Education, 56 (3), pp. 205-213.

Best, J.W. and Kahn, J., 1997, Research in Education, New Delhi: Prentice-Hall (7th Ed).

Bridget, Somekh. and Cathy Lewin., 2005, Research Methods in the Social Sciences, Book published by Vistaar Publications, New Delhi.

Campbell, J., Kyriakides, L., Muijs, D and Robinson, W., 2004, Accessing Teachers Job Effectiveness: Developing a Differentiated Model, New York; Routledge Falmer.

Case, Anne and Deaton Angus. (Aug 1999). 'School Inputs and Educational Outcomes in South Africa', Quarterly Journal of Economics, Vol. 114(3), August, pp. 1047-84.

Cooper, Ron A. and Weekes, Tony J., 1983, Book on Data, Models and Statistical Analysis, published in the USA by Barnes \& Noble Books, New Jersey.

Creswell, J.W., 1998, Qualitative Inquiry and Research Design: Choosing Among Five Traditions, London: Sage Publication.

Daniel, WW., 1999, Biostatistics: A Foundation for Analysis in the Health Sciences, 7th edition, New York, John Wiley \& Sons.

Dee, T.S., 2007, Teachers and the Gender Gaps in Student Achievement, Journal of Human Resources, University of Wisconsin Press, Vol. 42(3).

Glewwe, Paul. and Kremer, Michael., 2008, Schools, Teachers, and Education Outcomes in Developing Countries, in Hanushek, Eric. and Finis, Welch, eds., Handbook of the Economics of Education, Vol. 2. Amsterdam: North Holland, Chapter 16, pp. 945-1017.

Government of India, 2011, Census of India, Registrar General of India,

Government of NCT of Delhi, 2012-13, Delhi Economic Survey, Planning Department.

Government of NCT of Delhi, 2013, Delhi Statistics Handbook, Directorate of Economics and Statistics.

Hanushek, E.A., Kimko, D.D., 2000, Schooling, Labor-Force Quality, and the Growth of Nations, American Economic Review, 90(5), pp. 1184-1208.

Hanushek, Erik A., 2002, Teacher Quality, Hoover Press, http://wwwhoover.stanford.edu/publications/books/teacher.html\#toc.

Heck, R. H., 2007, Examining the Relationship Between Teacher Quality as an Organizational Property of Schools and Students' Achievement and Growth Rates, Educational Administration Quarterly, 43 (4), pp. 399342.

Johnson, S.M., 1990, Teachers at work: Achieving success in our schools, Boston: Basic Books.

Kothari, C.R., 1985, Research Methodology- Methods and Techniques, Wiley Eastern Limited, New Delhi. 
Krejcie, Robert V. and Morgan, Daryle W., 1970, Determining Sample Size for Research Activities, Educational and Psychological Measurement, 1970, 30, pp. 607-610.

Kremer, Michael. Muraldhiran, Karthik. Chaudhury, Nazmul. Hammer, Jeffrey and Rogers, F. Hasley., 2005, Teacher Absence in India: A Snapshot, Journal of the European Economic Association.

Kristin Grayson., 2005, Defining Teaching Quality Beyond the Certificate, Teacher Education (2005) 56 (3), pp. 205-213.

http://www.idra.org/IDRA_Newsletter/February_2009_Teaching_Quality/Defining_Teaching_Quality_Beyond _the_Certificate/\#sthash.MPZyIdrR.dpuf.

Lazear, E.A., 2003, Teacher Incentives, Swedish Economic Policy Review, 10(3), pp. 179-214.

Lydiah, L.M. and Nasongo, J.W., 2009, Role of the Head Teacher in Academic Achievement in Secondary Schools in Vihiga District, Kenya, Current Research Journal of Social Sciences 1(3): pp. 84-92, 2009, ISSN: 2041-3246.

Marlow, C., 1993, Research Methods, Pacific Grove, CA: Brooks/Cole.

Marshall, Catherine. and Rossman, Gretchen B., 2006, Designing Qualitative Research, Thousand Oaks: Sage Publication, 262 pages (4th edition), Social Science.

Nwachukwu, Prince Ololube., 2006, School Effectiveness and Quality Improvement: Quality Teaching in Nigerian Secondary Schools, University of Helsinki, Helsinki.

Ogunmade, Taiwo Oludare., Oct 2005, The Status and Quality of Secondary Science Teaching and Learning in Lagos State Nigeria, Research Thesis work submitted at Education and Social Science, Edith Cowan University, Perth, Western Australia.

Okoye, N.S., and S.O. Momoh, D.O. Aigbomian, R.E. Okecha., 2008, Teachers' Quality, Instructional Strategies and Students' Performance in Secondary School Science, Journal of Instructional Psychology, 34 (4), pp. 204-211.

Perry, P., 1994, Defining and Measuring the Quality of Teaching, In Green, D (Ed), What is Quality in Higher Education? Bristol: SRHE and Open University Press.

Raudenbush, S.W., Rowan, B., and Cheong, Y.F., 1992, Contextual effects on the self-perceived efficacy of high school teachers, Sociology of Education, 65, April, pp. 150-167.

Rivkin, S.G., Hanushek, E.A., and Kain, J.F., 2005, Teachers, Schools and Academic Achievement, Econometrica, 73(2), pp. 417-458.

Ross, Kenneth N., 2005, Quantitative Research Methods in Educational Planning, UNESCO International Institute for Educational Planning.

Summers, A. and Wolfe, B., 1977, Do Schools Make a Difference? American Economic Review, 67, pp. 639652.

Sungoh, S M., 2010, Quality Issues in Teacher Education, University News, 43(18), 2-8 May.

Susan H. Landry., 2016, Definition of "quality" teaching, Newsletter published by Harvard Graduate School of Education, Harvard Education Publishing Group, http://hepg.org/hel-home/susan-h-landry-on-the-definition-ofquality\%E2\%80\%9D-teach.

Taylor, S. J. and Bogdan, R., 1998, In-depth interviewing, In S J Taylor \& R Bogdan (eds) Introduction to Qualitative Research Methods: A Guidebook and Resource John Wiley and Sons.

Torff, B., 2005, Getting it Wrong on Threats to Teacher Quality, Phi Delta Kappan, 87 (4), pp. 302-305.

Wekesa, G.W., 1993, The Impacts of Head Teachers' Instructional Leadership on Student Academic Achievement in Kenya, Columbia, Columbia University. 